\title{
Gel electrolytes based on polyacrylonitrile/thermoplastic polyurethane/polystyrene for lithium-ion batteries
}

\author{
$\mathrm{Li} \mathrm{Tan}^{1} \cdot$ Yuanyuan Deng ${ }^{1} \cdot$ Qi Cao ${ }^{1} \cdot$ Bo Jing ${ }^{1} \cdot$ Xianyou Wang ${ }^{1} \cdot$ Yuewen Liu $^{1}$
}

Received: 25 November 2018 / Revised: 18 February 2019 / Accepted: 20 February 2019 / Published online: 3 April 2019

(C) The Author(s) 2019

\begin{abstract}
Using an electrospinning method, high-performance gel polymer electrolytes (GPEs) comprising polyacrylonitrile/ thermoplastic polyurethane/polystyrene (PAN/TPU/PS) were prepared. Then, these electrolytes were used to assemble button cells. The GPEs exhibited a maximum ionic conductivity of $3.9 \times 10^{-3} \mathrm{~S} \mathrm{~cm}^{-1}$ at room temperature, with an electrochemical stability of $5.8 \mathrm{~V}$. In addition, a $\mathrm{Li} / \mathrm{GPE} / \mathrm{LiFePO}_{4}$ cell showed first charge and discharge capacities of $161.70 \mathrm{mAh} \mathrm{g}^{-1}$ and $161.44 \mathrm{mAh} \mathrm{g}^{-1}$, respectively, at a $0.1 \mathrm{C}$ rate and a stable cycle performance (the capacity retention was nearly $94 \%$ after 50 cycles) with high coulombic efficiency. Additionally, the SEM images showed that the PAN/ TPU/PS was not composed of beaded-fibres in a fibrous membrane but was composed of fibres that were slim with a uniform size distribution. The uptake behaviour and porosity of the PAN/TPU/PS fibres showed the best performance and superior physical properties of the tested samples (the elongation at break of the film was $115.15 \%$, and the tensile strength was $9.86 \mathrm{MPa}$ ). Considering these results, the PAN/TPU/PS blend/composite film has broad prospects for use in lithium-ion batteries.
\end{abstract}

Keywords Electrospinning $\cdot$ Gel polymer electrolyte $\cdot$ Polyacrylonitrile $\cdot$ Thermoplastic polyurethane $\cdot$ Polystyrene

\section{Introduction}

With the consumption of non-renewable resources, such as petroleum and coal, lithium-ion batteries (LIBs) have received attention as the first of the new energy technologies. The electrolyte is an important component of LIBs, and its chemical stability and safety are important factors in guaranteeing a long cycle life and high security for the LIBs [1-4]. Gel polymer electrolytes (GPEs) [5-7] not only have the high ionic conductivities of liquid electrolytes [8-10] but also have a series of advantages, such as solving the difficult problem of electrolyte leakage, flammability, and explosivity [11]. However, the application of gel polymer electrolytes in LIBs is still difficult $[12,13]$ because of their problems such as low ionic conductivities and poor mechanical strengths at room temperature.

Qi Cao

wjcaoqi@163.com

1 Key Laboratory of Environmentally Friendly Chemistry and Applications of Minister of Education, College of Chemistry, Xiangtan University, Xiangtan 411105, China
Polyacrylonitrile (PAN) [14-18] has outstanding properties, such as high thermal stability, high ionic conductivity, good compatibility with lithium electrodes, a wellformed morphology for electrolyte absorption, and the ability to minimise dendritic formation during the charge and discharge processes. PAN is superior to poly(vinylidene fluoride) (PVDF) $[19,20]$ because of its interfacial properties and minimization of dendritic growth [21]. The $\mathrm{C} \equiv \mathrm{N}$ groups in PAN can interact with the lithium-ions and $\mathrm{C}=\mathrm{O}$ groups of ethylene carbonate (EC), which makes it more versatile for a variety of applications [22]. However, there severe interfacial passivation occurs between PAN-based gel polymer films and lithium electrodes. Additionally, the mechanical properties of PAN decrease as the contents of the plasticiser increase [23]. Therefore, PAN cannot be used as a free-standing membrane in lithium-ion batteries. Therefore, to improve the mechanical stability, PAN has always been modified via copolymerization or blending with other materials.

Thermoplastic polyurethane (TPU) is an elastomer that has a high tensile strength, high elasticity, and low crystallinity [24, 25]. Having good mechanical properties of flexibility and rigidity is very important for LIB 
membranes. TPU has a two-phase microstructure with soft segments and hard segments [26-29]. The hardphase segments are connected to the soft-phase segments and retain their spatial stability due to $\pi-\pi$ interactions and hydrogen bonding between the urethane groups. The soft segments, which possess with ether type of bond, can support ionic liquids, which is favourable for promoting the dissociation of alkali metal salts, thereby enhancing the ionic conductivity. The soft segments are physically cross-linked, ensuring good film-forming and good mechanical properties of the films. TPU is widely used in various industrial fields owing to its superior physical performance, chemical resistance, abrasion resistance, good adhesion, and ease of processing [30-34]. Therefore, TPU was selected as a matrix component in this report to ensure the stable electrochemical performance and good mechanical properties of the electrolyte.

Polystyrene (PS) is a traditional thermoplastic polymer that has the features of ease of processing, colourlessness, transparency, and high strength. Therefore, it is widely used in industrial production [35-37]. PS has excellent mechanical properties, such as high strength, fatigue resistance, and spatial stability. In addition, PS has a high glass transition temperature and a high breakdown field.

Therefore, PAN, TPU, and PS were used as matrix materials in this research to prepare PAN/TPU/PS, PAN/TPU, PAN/PS, and TPU/PS blend/composite films by an electrospinning technique. The physical and electrochemical properties of these films were investigated.

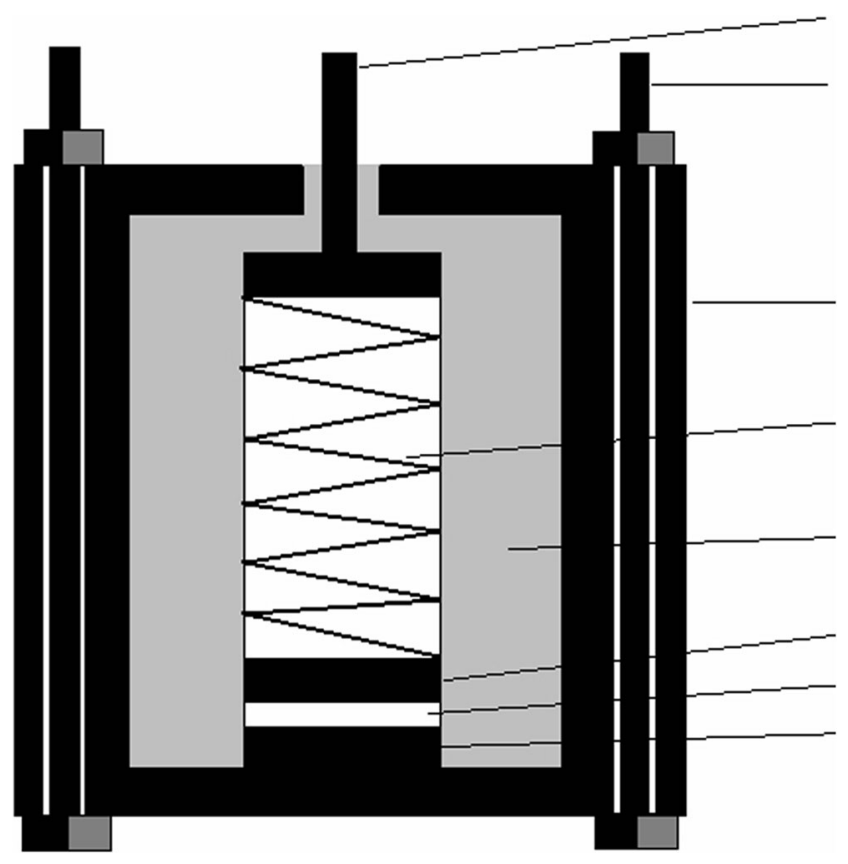

Fig. 1 The installation diagram of the assembled cell

\section{Materials and methods}

\section{Materials}

Polyacrylonitrile (PAN, average $M_{\mathrm{w}}=150,000$ ) was supplied by Sigma-Aldrich. Thermoplastic polyurethane (TPU) was provided by Wanhua Company, and polystyrene (PS) was purchased from BASF. All raw materials were dried at $60{ }^{\circ} \mathrm{C}$ under vacuum for $12 \mathrm{~h}$ before use.

\section{Preparation of the PAN/TPU/PS nanofibrous membrane}

A certain amount of PAN, TPU, and PS (mass ratio of 5:5:1) were homogeneously dissolved in DMF to prepare a solution with a mass fraction of $10 \%$. The solution was stirred for $12 \mathrm{~h}$ at $60^{\circ} \mathrm{C}$. PAN/TPU, PAN/PS, and TPU/PS solutions with $10 \%$ mass fractions were prepared by the same method. The mixture was transferred to a syringe and electrospun at a flow rate of $0.5 \mathrm{~mL} \mathrm{~h}^{-1}$. The nozzle tip voltage was maintained at $24 \mathrm{kV}$, and the collector was at room temperature. The blend/composite films were dried at $60{ }^{\circ} \mathrm{C}$ under vacuum for $12 \mathrm{~h}$.

\section{Preparation of the gel polymer electrolytes}

The dried blend/composite films were impregnated in a $1 \mathrm{~mol} \mathrm{~L}^{-1} \mathrm{LiPF}_{6}-\mathrm{EC} / \mathrm{DMC}$ electrolyte to convert them into GPEs in a glove box with a high-purity argon atmosphere.

\section{The physical properties of the membranes}

The morphologies of the membranes were studied by scanning electron microscopy (SEM) (Hitachi S-3500N, Japan). The material structures and chemical compositions were analysed by Fourier transform infrared spectroscopy (FTIR) (Spectrum One, PerkinElmer Instruments). The thermal properties of the fibrous films were tested by thermogravimetric analysis (model TGA Q50, TA Company, USA). Thermogravimetric analysis (TGA) measurements were carried out from 30 to $800{ }^{\circ} \mathrm{C}$ at a rate of $20^{\circ} \mathrm{C} / \mathrm{min}$ under a dry nitrogen atmosphere. The porosities of the films were calculated by formula (1):

$$
P=\frac{W_{w}-W_{d}}{\rho_{b} V_{p}} \times 100 \%
$$

where $W_{w}$ and $W_{d}$ are the weights of the wet and dry separators, respectively, $\rho_{b}$ is the density of n-butanol, and $V_{p}$ is the volume of the dry film.

The absorption percentage of the electrolyte can be calculated by formula (2). 
Fig. 2 SEM images of the electrospun films: a PAN/PS, b PAN/TPU, $\mathbf{c}$ TPU/PS, and $\mathbf{d}$ $\mathrm{PAN} / \mathrm{TPU} / \mathrm{PS}$
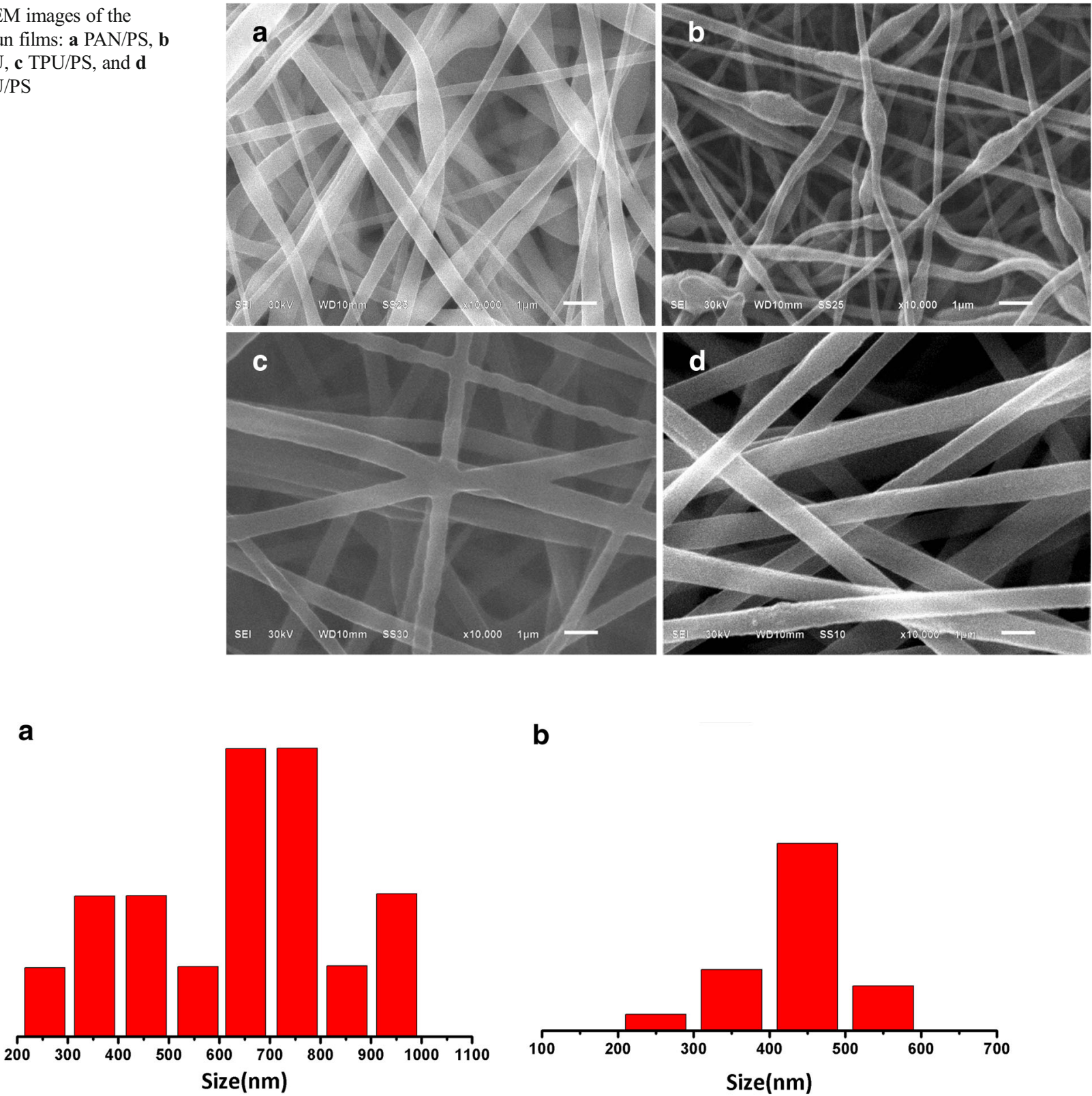

b

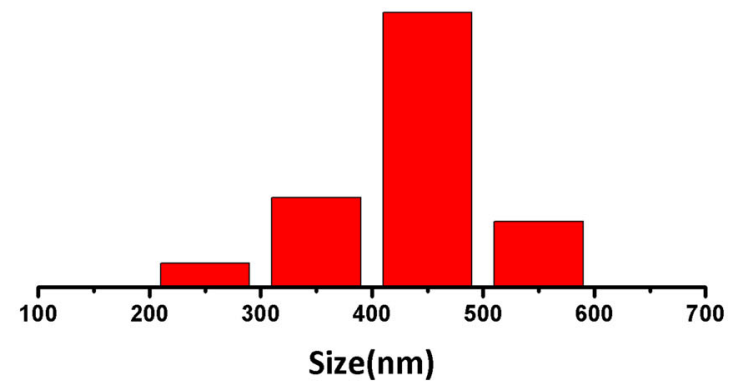

C

d
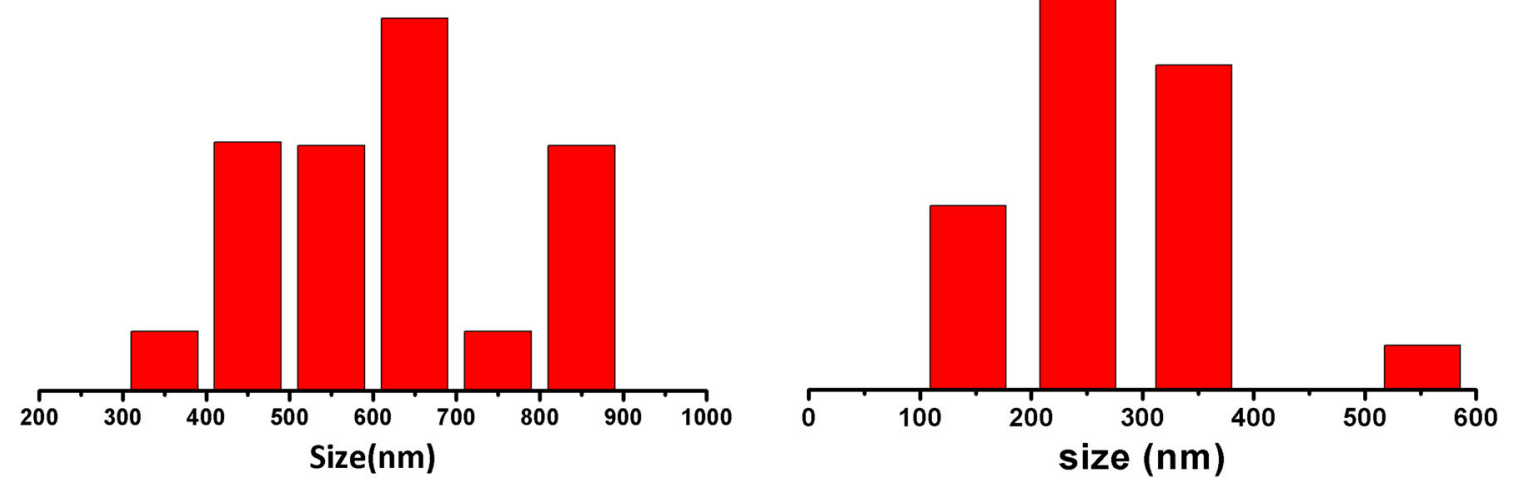

Fig. 3 Size of the electrospun films: a PAN/PS, b PAN/TPU, $\mathbf{c}$ TPU/PS, and $\mathbf{d}$ PAN/TPU/PS 


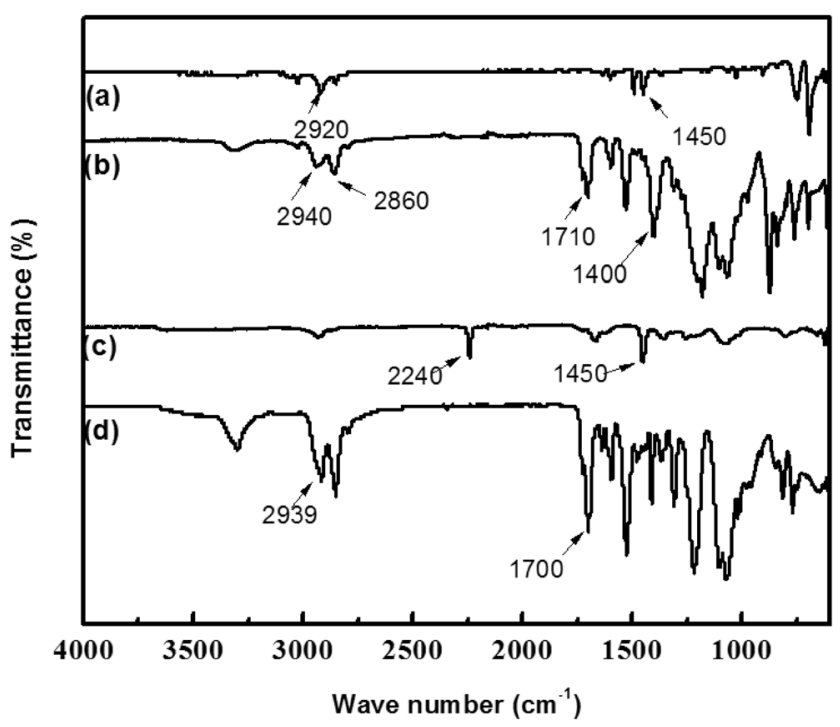

Fig. 4 Infrared spectra a PS, b TPU, c PAN, and d PAN/TPU/PS

$\operatorname{Uptake}(\%)=\frac{W-W_{0}}{W_{0}} \times 100 \%$

In this equation, $W_{0}$ is the weight of the dry electrospun fibre membrane, and $W$ is the weight of the wet film after the dry membrane is impregnated into the $1 \mathrm{~mol} / \mathrm{L} \mathrm{LiPF}_{6}-\mathrm{EC} /$ DMC electrolyte.

The mechanical strengths of the films were tested at an elongation rate of $5 \mathrm{~mm} / \mathrm{min}$ using an electronic tensile machine (Riegel, RGM-6005) after cutting the electrospun films into a width of $2 \mathrm{~cm}$ and a length of $5 \mathrm{~cm}$ and a thickness of $100-150 \mu \mathrm{m}$. The elongation at break is calculated by the following formula:

$$
\text { Strain }(\%)=\frac{L}{L_{0}} \times 100 \%
$$

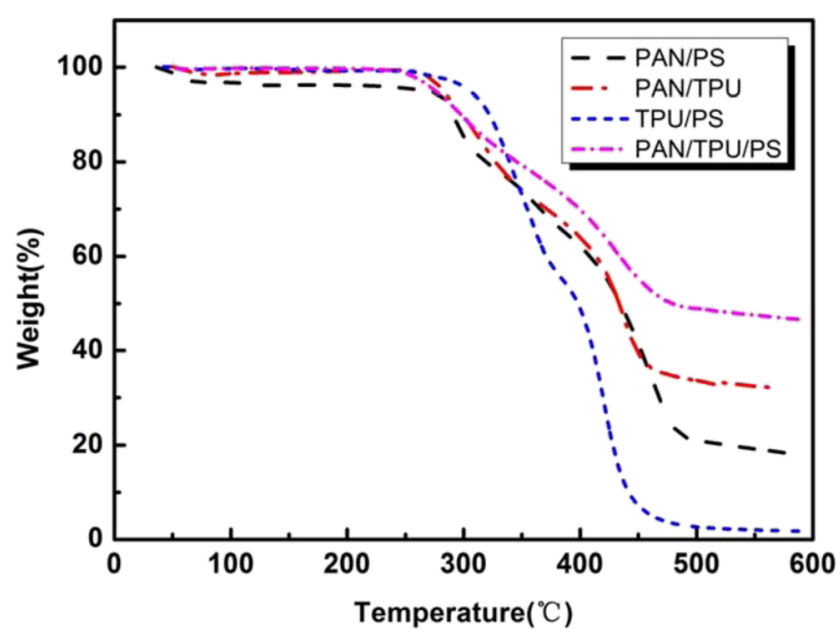

Fig. 5 TGA curves of the electrospun fibre films where $L_{0}$ is the initial distance between the measuring moulds (mm).

The tensile strength is calculated by the following formula:

Stress $=\frac{F}{S}$

where $S$ is the cross-sectional area $\left(\mathrm{mm}^{2}\right)$.

Thermal shrinkage primarily refers to the thermoplastic material due to its inherent thermal expansion rate of volume change, which is the main reason for the contraction. In the test, the blend/composite films prepared in this experiment were pressed into a disc with a diameter of $19 \mathrm{~mm}$, heated at $180^{\circ} \mathrm{C}$ for $1 \mathrm{~h}$, and the changes in their diameter and curl were measured.

\section{Performance of the assembled cells}

Figure 1 shows the installation diagram of a cell. The electrospun membranes were assembled into batteries according to this cell structure for the following experiments. Electrochemical impedance spectroscopy (EIS) was carried out by an electrochemical analyser (CHI660A, Shanghai Chenhua) with a frequency range from $10^{-2}$ to $10^{5} \mathrm{~Hz}$. The ionic conductivity was then determined according to the following Eq. (5):

$$
\sigma=\frac{h}{R_{b} S}
$$

In this equation, $\sigma$ is the ionic conductivity, $R_{b}$ represents the bulk resistance of the membrane, $h$ is the thickness, and $S$ is the area. The charge and discharge tests of the button batteries were conducted by a Neware (model BTS-51, Shenzhen, China) battery tester with a test voltage of 2.0 $4.2 \mathrm{~V}$, and a cycle number of 50 . Electrochemical stability was studied by linear sweep voltammetry (LSV). A Zahner Zhex electrochemical analyser was set to a scanning rate of $5 \mathrm{mVs}^{-1}$ and a voltage range of $0-7 \mathrm{~V}$ to study the coin cells.

\section{Results and discussion}

\section{Morphology and structure}

Figure 2 shows SEM images of the PAN/PS, PAN/TPU, TPU/PS, and PAN/TPU/PS electrospun films. The binary electrospun films (PAN/PS, PAN/TPU, and TPU/PS) have a variety of problems. The fibre diameter size of PAN/PS (Fig. 3a) has an uneven distribution, with an average fibre diameter of approximately $691 \mathrm{~nm}$. The electrospun film of PAN/TPU (Figs. $2 \mathrm{~b}$ and $3 \mathrm{~b}$ ) has beads, with diameter values ranging between 180 and 
Table 1 Liquid absorptivity, ionic conductivity, and porosity of the different films

\begin{tabular}{lllllll}
\hline Sample & $\begin{array}{l}\text { Surface } \\
\text { area }\left(\mathrm{cm}^{2}\right)\end{array}$ & $\begin{array}{l}\text { Thickness } \\
(\mathrm{cm})\end{array}$ & $\begin{array}{l}\text { Uptake } \\
\text { behaviour }(\%)\end{array}$ & $\begin{array}{l}\text { Resistance } \\
(\Omega)\end{array}$ & $\begin{array}{l}\text { Ionic conductivity } \\
(\mathrm{mS} \mathrm{cm})\end{array}$ & $\begin{array}{l}\text { Porosity } \\
(\%)\end{array}$ \\
\hline PAN/PS & 2.01 & 0.0155 & 250 & 3.69 & $2.08 \times 10^{-3}$ & 57 \\
TPU/PS & 2.01 & 0.014 & 148 & 2.77 & $2.51 \times 10^{-3}$ & 62 \\
PAN/TPU & 2.00 & 0.015 & 201 & 2.43 & $3.08 \times 10^{-3}$ & 67 \\
PAN/TPU/PS & 2.01 & 0.015 & 315 & 1.76 & $4.24 \times 10^{-3}$ & 82 \\
\hline
\end{tabular}

$570 \mathrm{~nm}$. Moreover, Fig. 2c shows that there is crosslinking in the electrospun film of TPU/PS, with the diameter values ranging from 380 to $870 \mathrm{~nm}$ (Fig. 3c). The average fibre diameter of TPU/PS is approximately $615 \mathrm{~nm}$. Figure 2d shows that the fibres of the PAN/ TPU/PS electrospun film are slim and uniform in diameter. The minimum diameter of the fibres is $282 \mathrm{~nm}$, and the maximum diameter is $510 \mathrm{~nm}$ (Fig. 3d).

Under the same conditions (voltage, receiving distance, flow rate, and temperature), the viscosity and conductivity of the electrospinning solution affect the morphology of the electrospun film. Increasing the amounts of PAN and TPU causes an increase in the ionic conductivity of the mixture for electrospinning because of the high ionic conductivities of PAN and TPU. The increased conductivity of the solution allows the polymer droplets to be fully stretched under the influence of a high electric field force, forming more uniform fibres. As shown in Fig. 3b, the minimum diameter of the fibre is $180 \mathrm{~nm}$. When the solution viscosity is low, beads appear in the fibres, such as those in Fig. 2b. This is because the molecular chains are not effectively stretched during spinning. Therefore, the fibres of PAN/TPU (Fig. 2b) have beads. With the addition of PS, the viscosity of the spinning solution increases, and the molecular chains are fully extended in the electrospinning process, such that the fibres have good

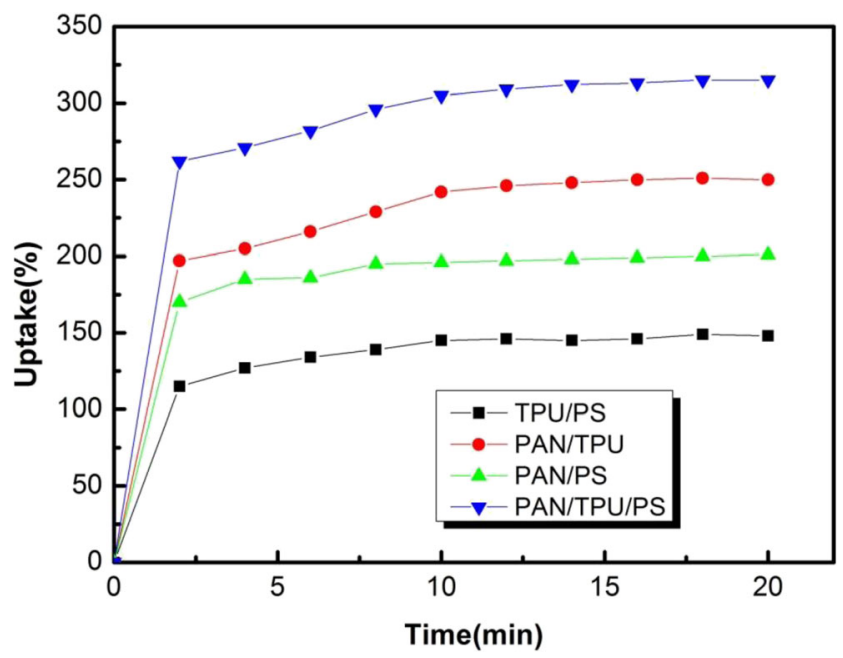

Fig. 6 Uptake behaviours of the four electrospun membranes morphologies [38]. In addition, the ternary polymer solution greatly reduces the surface tension [39]. The mixed solution is thus completely stretched during the spinning process to form a smooth fibre. Therefore, PAN/PS, PAN/ TPU, and TPU/PS electrospun films have certain visual defects, while the PAN/TPU/PS film has a very good appearance. We boldly speculate that the ternary blended PAN/TPU/PS electrospun membranes will have excellent electrochemical properties.

\section{Infrared spectrum analysis}

The FTIR spectra of PS, PAN/TPU/PS, PAN, and TPU are shown in Fig. 4. The characteristic absorption peaks of PS are observed at $2920 \mathrm{~cm}^{-1}$ (stretching band of $\mathrm{CH}_{2}-$ in the benzene ring) and $1450 \mathrm{~cm}^{-1}$ (stretching band of $\mathrm{C}-\mathrm{C}$ in the benzene ring). This is because the polystyrene polymerisation reduces the carbon-carbon double bonds into single bonds during intermolecular polymerisation. The characteristic absorption peaks of TPU can be identified at $2939 \mathrm{~cm}^{-1}$ (stretching band of $-\mathrm{NH}_{2}$ in the hard phase) and $1700 \mathrm{~cm}^{-1}$ (stretching band of $\mathrm{C}=\mathrm{O}$ ). The typical peaks of PAN are at $2240 \mathrm{~cm}^{-1}$ (stretching band of $\mathrm{C} \equiv \mathrm{N}$ ) and $1450 \mathrm{~cm}^{-1}$ (deformation vibration band of $-\mathrm{CH}_{2}-$ ). However, in the case of the electrospun membrane of PAN/TPU/PS, the characteristic absorption peaks of TPU and PAN are shifted to 2940, 2860, 1710, and $1400 \mathrm{~cm}^{-1}$. This originates from the repulsive dipolar interactions between the $\mathrm{C}=\mathrm{O}$ groups of TPU and the $\mathrm{C} \equiv \mathrm{N}$ groups of PAN. Furthermore, it is possible that the presence of PAN in the composites modified the hard-hard segment interactions of TPU, which consequently resulted in a new morphology of TPU with altered hydrogen-bonding characteristics between the hard-hard segments.

\section{Thermal analysis}

Thermograms of the different electrospun films are shown in Fig. 5. The PAN/TPU/PS film and the PAN/TPU film began to decompose at $260{ }^{\circ} \mathrm{C}$. The PAN/PS began to decompose at $280{ }^{\circ} \mathrm{C}$. The initial decomposition temperature of TPU/PS was $300{ }^{\circ} \mathrm{C}$, but the quality of the fibre film rapidly declined between 300 and $450{ }^{\circ} \mathrm{C}$, and the quality retention of TPU/PS 
Fig. 7 Impedance spectra of the gel polymer electrolytes

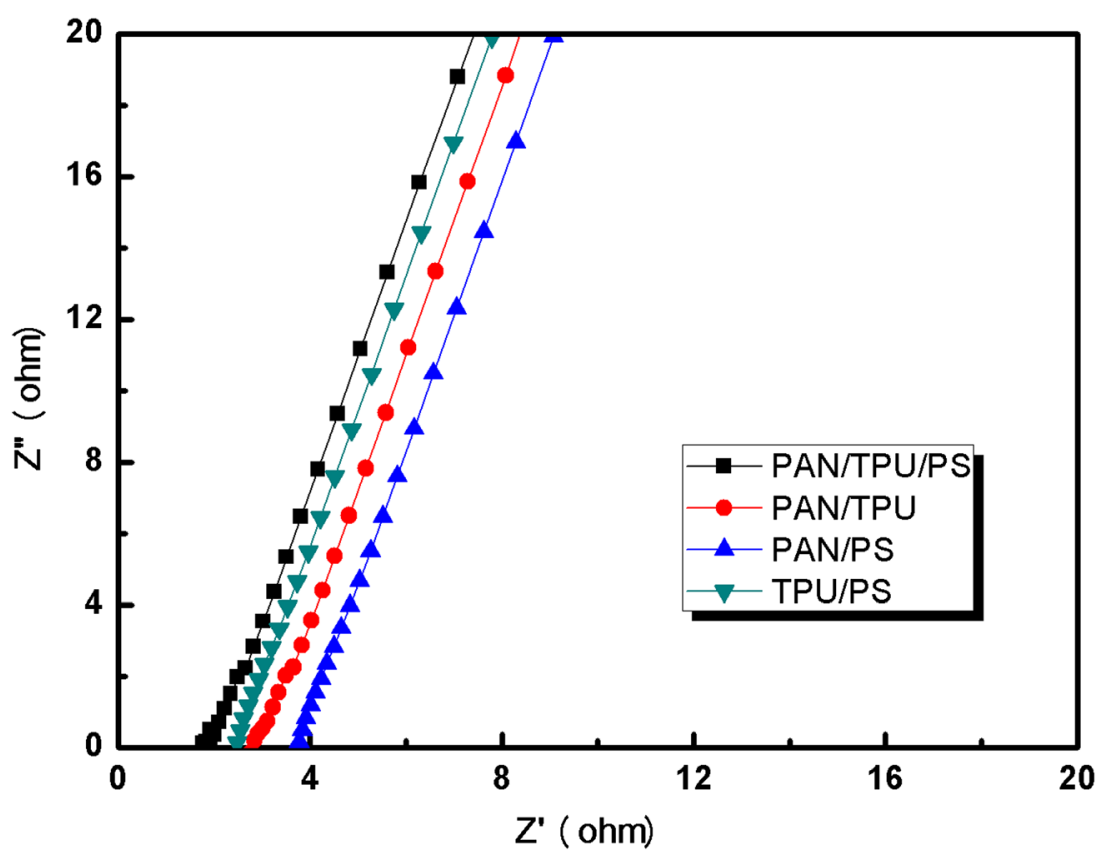

was the lowest of the films. The retention percentages of the four blend/composite films (TPU/PS, PAN/PS, PAN/TPU, and PAN/TPU/PS) were $1.8 \%, 18 \%, 32 \%$, and $47 \%$ at $600{ }^{\circ} \mathrm{C}$, respectively. The TPU/PS film was nearly completely decomposed.

These results show that the PAN/TPU/PS membrane has better thermal stability than that of the other samples. In addition, when the temperature is lower than $260{ }^{\circ} \mathrm{C}$, the four electrospun films hardly decompose thermally. Compared with the other films, a slight enhancement in the thermal stability of PAN/TPU/PS in the temperature range of 300 to $450{ }^{\circ} \mathrm{C}$ is observed, which is due to the introduction of PAN. The interaction between PAN and TPU promotes thermal stability. It is clear that the PAN/TPU/PS film is suitable for use in lithium-ion batteries as a separator.

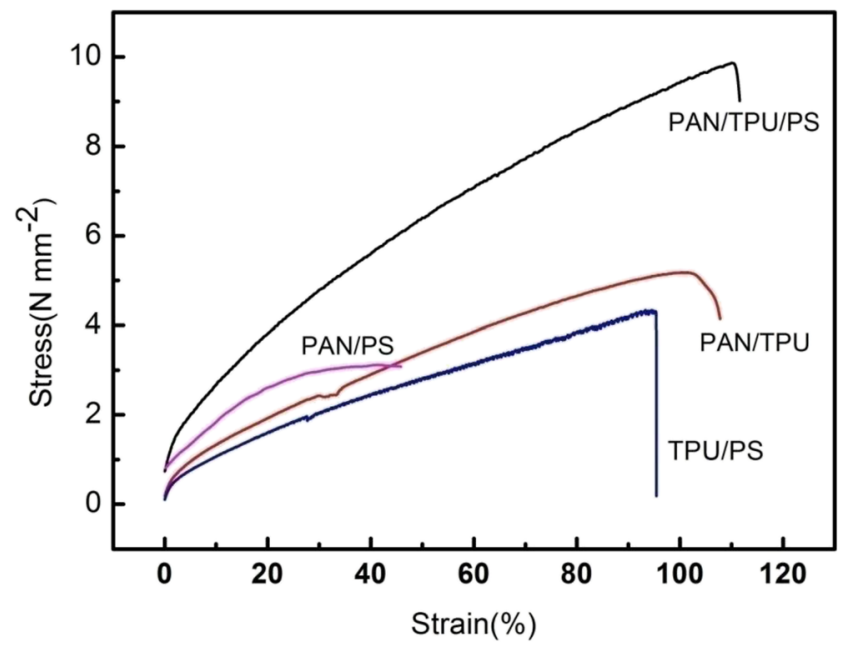

Fig. 8 Stress-strain curves of the four electrospun films

\section{Porosity, electrolyte uptake, and ionic conductivity}

Table 1 shows the liquid absorptivity, ionic conductivity, and porosity of the different films. Porosity is calculated from Eq. (1). These results verify the structure of the four electrospun films as shown in the SEM images. The porosities of the PAN/ PS, PAN/TPU, TPU/PS, and PAN/TPU/PS fibre films are $57 \%, 67 \%, 62 \%$, and $82 \%$, respectively. It is obvious that the average fibre diameter of the ternary-blend PAN/TPU/PS film is the smallest, and its specific surface area and porosity are the largest.

The percentage of electrolyte uptake can be calculated according to Eq. (2). As shown in Fig. 6, the liquid absorption rate of the ternary-blend PAN/TPU/PS electrospun film is the largest among the four samples for the fluid uptake tests. The reason for this is that the material has a higher porosity than the other films. This structure is conducive to the rapid adsorption of the liquid electrolyte. The liquid absorbencies of the TPU/PS, PAN/PS, PAN/TPU, and PAN/TPU/PS fibre membranes are $140 \%, 190 \%, 245 \%$, and $310 \%$, respectively. The fastest liquid absorbency rates of all the electrospun films occurred within the first $2 \mathrm{~min}$.

Figure 7 shows the electrochemical impedance spectroscopy (EIS) of the gel polymer electrolytes with different matrices. It can be observed from Fig. 8 that the bulk resistance $\left(R_{\mathrm{b}}\right)$ of the PAN/PS polymer electrolyte is $3.69 \Omega$. Correspondingly, the bulk resistance of the PAN/TPU and TPU/PS electrolytes is $2.43 \Omega$ and $2.77 \Omega$, respectively. However, the bulk resistance $\left(R_{\mathrm{b}}\right)$ of the PAN/TPU/PS GPE is only $1.76 \Omega$. The ionic conductivities can be calculated with Eq. (5). The gel polymer electrolyte films have ionic conductivities of $2.08 \times$ 
Table 2 Mechanical properties of all the electrospun fibrous membranes

\begin{tabular}{lllll}
\hline Sample & Surface area $\left(\mathrm{cm}^{2}\right)$ & Thickness $(\mathrm{cm})$ & Tensile strength $(\mathrm{MPa})$ & Elongation at break $(\%)$ \\
\hline PAN/PS & 1.99 & 0.016 & $3.10 \pm 0.2$ & $43.05 \pm 0.2$ \\
TPU/PS & 2.00 & 0.018 & $4.31 \pm 0.2$ & $95.26 \pm 0.2$ \\
PAN/TPU & 2.00 & 0.016 & $5.18 \pm 0.2$ & $100.58 \pm 0.2$ \\
PAN/TPU/PS & 1.99 & 0.018 & $9.86 \pm 0.2$ & $115.15 \pm 0.2$ \\
\hline
\end{tabular}

$10^{-3} \mathrm{~S} \mathrm{~cm}^{-1}$ (PAN/PS), $3.08 \times 10^{-3} \mathrm{~S} \mathrm{~cm}^{-1}$ (PAN/TPU), $2.51 \times 10^{-3} \mathrm{~S} \mathrm{~cm}^{-1}(\mathrm{TPU} / \mathrm{PS})$, and $4.24 \times 10^{-3} \mathrm{~S} \mathrm{~cm}^{-1}$ (PAN/TPU/PS).

The ionic conductivity is dependent on the porosity of the fibrous membrane. The ionic conductivity increases as the $\mathrm{Li}^{+}$ amount increases, which results from a higher electrolyte uptake and porosity of the film. Furthermore, it was found that the average diameter of the PAN/TPU/PS nanofibres was the smallest and most uniform of the different fibres based on the SEM measurements. Therefore, the electrolyte uptake and porosity of the PAN/TPU/PS GPE are great. This may be the reason for the resistance of the PAN/TPU/PS being the lowest of the samples. In summary, the PAN/TPU/PS GPE has the highest ionic conductivity of the different samples and should be suitable for application in lithium-ion batteries.

\section{Mechanical performance}

The mechanical properties of the electrospun films are shown in Fig. 8. The test results show that the mechanical properties of the membranes are improved by the inclusion of TPU and PS fillers. The PAN/PS membrane extended only $43.05 \%$ with a poor breaking tensile strength of $3.10 \mathrm{MPa}$. The PAN/TPU membrane without PS extended $100.58 \%$ with a poor breaking tensile strength of $5.18 \mathrm{MPa}$. However, the membrane

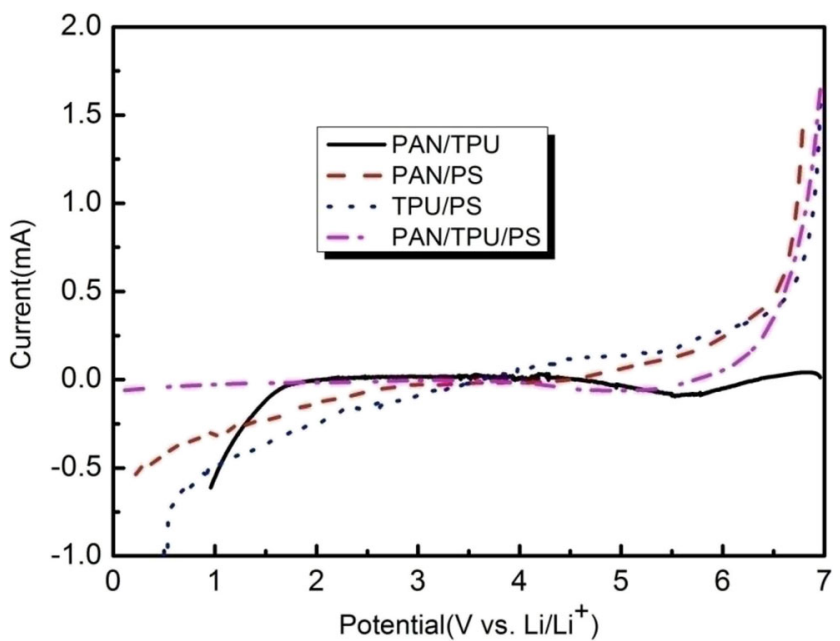

Fig. 9 Linear sweep voltammograms of the gel polymer electrolytes based on the electrospun membranes composed of PAN/TPU/PS has $86.4 \%$ elongation and broke under a tensile strength of $10.8 \mathrm{MPa}$. All these data are included in Table 2. The increase in fracture strength and elongation at break of the PAN/TPU/PS film can be attributed to the addition of TPU and PS. TPU is an elastomer with a high tensile strength and elasticity, and PS has excellent mechanical properties, including high strength, fatigue resistance, and spatial stability. TPU and PS are included to maintaining the spatial stability of the PAN/TPU/PS film. Thus, the PAN/ TPU/PS ternary-blend membrane shows excellent mechanical properties.

\section{Electrochemical stability}

Figure 9 shows the LSV curves of the gel polymer electrolytes. It can be seen that the electrochemical stability of the gel polymer electrolyte with the PAN/TPU/PS membrane is $5.8 \mathrm{~V}$. The electrochemical stability plateaus of the PAN/TPU and PAN/PS fibrous polymer electrolytes occur at $4.2 \mathrm{~V}$ and 3.7 V, while the curve of the TPU/PS GPE continuously changes. As we can see from Fig. 9, the electrochemical stabilities are ranked as follows: the polymer film of PAN/TPU/ $\mathrm{PS}(5.8 \mathrm{~V})>\mathrm{PAN} / \mathrm{TPU}(4.2 \mathrm{~V})>\mathrm{PAN} / \mathrm{PS}(3.7 \mathrm{~V})$. It is clear that the gel polymer electrolyte comprising PAN/TPU/PS shows the best electrochemical stability, which is much higher than the requirements for practical application.

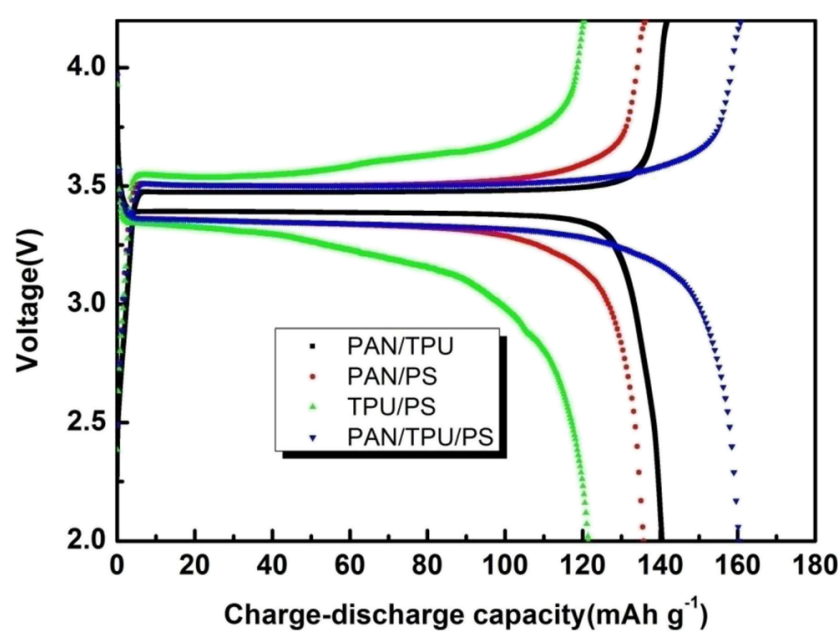

Fig. 10 First charge-discharge capacities of the GPEs based on the four different electrospun membranes 


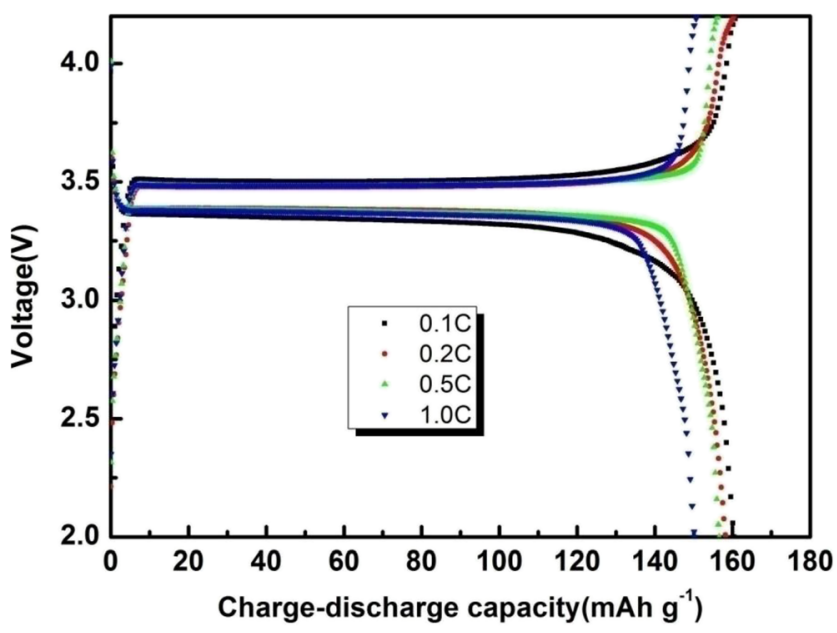

Fig. 11 First charge-discharge capacities of GPEs based on the electrospun PAN/TPU/PS membrane at different rates $(1 \mathrm{C}=$ $170 \mathrm{mAh} \mathrm{g}^{-1}$ )

There is almost no electrochemical reaction in the potential range from 2 to $5.8 \mathrm{~V}$ for the PAN/TPU/PS gel polymer electrolyte. When the electrode potential is greater than $5.8 \mathrm{~V}$, the response current significantly increases, indicating that the polymer electrolyte experiences an electrochemical reaction and the onset of decomposition. The large surface area of the PAN/TPU/PS membrane significantly contributes to the increased stability of the electrolyte solution under electrochemical environments. In addition, the better anodic stability of the PAN/TPU/PS-based GPE is in part due to its excellent affinity for the carbonates (EC and DMC) of the liquid electrolyte. The interactions between the $\mathrm{C}=\mathrm{O}$ groups of the carbonate molecules and the $-\mathrm{NH}$ groups of TPU or the $-\mathrm{CN}$ groups of PAN contribute significantly to the enhancement of the electrochemical stability. The above results demonstrate that the PAN/TPU/PS-based GPE has excellent

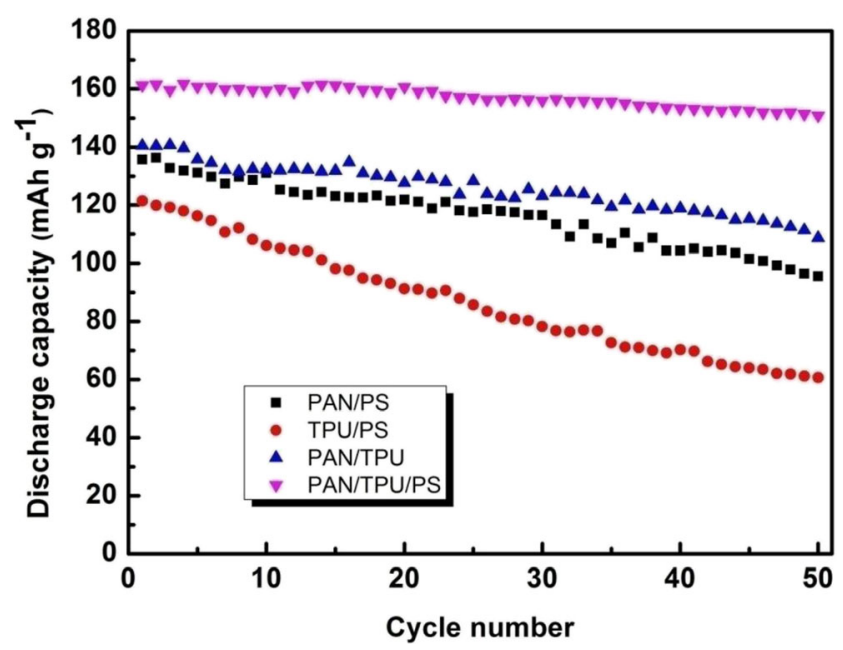

Fig. 12 The cycle performance (discharge capacity) of the GPE based on the electrospun PAN/TPU/PS membrane

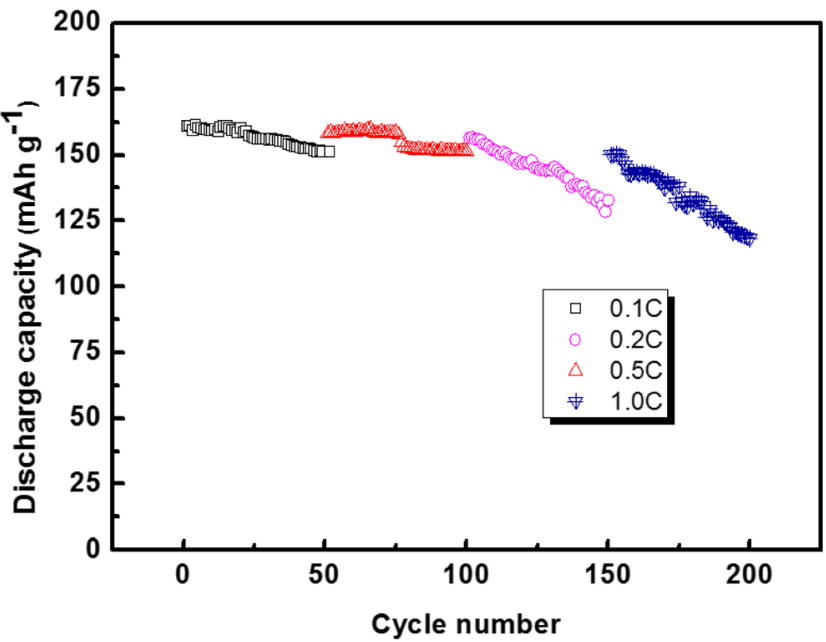

Fig. 13 Cycle performance of the PAN/TPU/PS GPE at different rates

electrochemical stability and is suitable for application in lithium-ion batteries.

\section{Evaluation in $\mathrm{Li} / \mathrm{LiFePO}_{4}$ cells}

As an active material, the theoretical specific capacity of $\mathrm{LiFePO}_{4}$ is $170 \mathrm{mAh} \mathrm{g}^{-1}$, which is typical of $\mathrm{LiFePO}_{4}$ [40]. Figure 10 shows the first charge-discharge capacity curves of $\mathrm{Li} / \mathrm{GPE} / \mathrm{LiFePO}_{4}$ using the different GPEs. The charge and discharge capacities of the PAN/TPU/PS GPE are $161.70 \mathrm{mAh} \mathrm{g}^{-1}$ and $161.44 \mathrm{mAh} \mathrm{g}^{-1}$, respectively, while the other three gel polymer electrolyte films deliver charge capacities of $141.79 \mathrm{mAh} \mathrm{g}^{-1}$ (PAN/TPU GPE), $135.98 \mathrm{mAh} \mathrm{g}^{-1}$ (PAN/PS GPE), and $121.37 \mathrm{mAh} \mathrm{g}^{-1}$ (TPU/PS GPE) and discharge capacities of $140.53 \mathrm{mAh} \mathrm{g}^{-1}$ (PAN/TPU GPE), $135.76 \mathrm{mAh} \mathrm{g}^{-1}$ (PAN/PS GPE), and $121.33 \mathrm{mAh} \mathrm{g}^{-1}$ (TPU/PS GPE). The gel polymer electrolyte film comprising PAN/TPU/PS has the best charge-discharge capacity, and a first charge-discharge efficiency of $95 \%$ of the theoretical capacity. This may be due to the large number of interpenetrating pores in the polymer electrolyte membrane, providing the necessary channels for ionic transport and facilitating rapid ionic transport. On the other hand, it may be a result of the compatibilities of PAN, TPU, and PS in the polymer matrix.

Additionally, as is shown in Fig. 11, we study the different rate capabilities of the PAN/TPU/PS GPE. At relatively high rates, the polymer film has a discharge capacity of $161.70 \mathrm{mAh} \mathrm{g}^{-1}(0.1 \mathrm{C}), 158.16 \mathrm{mAh} \mathrm{g}^{-1}(0.2 \mathrm{C})$, $156.58 \mathrm{mAh} \mathrm{g}^{-1}(0.5 \mathrm{C})$, and $150.07 \mathrm{mAh} \mathrm{g}^{-1}$ (1.0 C). As the rate increases, the current intensity increases correspondingly, resulting in high polarisation of the electrode material. Therefore, the capacity of the battery experiences different degrees of attenuation.

We further evaluate the cycle stabilities of the four different GPEs under a rate of $0.1 \mathrm{C}$ at $25^{\circ} \mathrm{C}$. It is obvious that at lower 
current rates $(0.1 \mathrm{C})$, the button-cell battery based on the PAN/ TPU/PS GPE retains $93.4 \%$ of its capacity after 50 cycles.

Figure 12 shows the cycle performances of polymer films at the $0.1 \mathrm{C}$ rate. After 50 cycles, the capacity retention percentages of the PAN/PS, PAN/TPU, and TPU/PS button cells are only $80.1 \%, 68.0 \%$, and $50.0 \%$, respectively. The button-cell battery based on the PAN/TPU/PS GPE has the largest capacity retention of the different batteries at $93.4 \%$. The button cell containing the PAN/TPU/PS GPE has the highest discharge capacity of the different batteries with a small capacitance decay, which clearly shows its superior cycle performance.

Figure 13 shows the cycle performance of the button cell based on the PAN/TPU/PS GPE at different rates. When the rates were $0.1 \mathrm{C}, 0.2 \mathrm{C}, 0.5 \mathrm{C}$, and $1.0 \mathrm{C}$, the first discharge capacities of the PAN/TPU/PS GPE were $161.44 \mathrm{mAh} \mathrm{g}^{-1}$, $156.58 \mathrm{mAh} \mathrm{g}^{-1}, 158.21 \mathrm{mAh} \mathrm{g}^{-1}$, and $150.17 \mathrm{mAh} \mathrm{g}^{-1}$, respectively. After 50 cycles, the discharge capacities were $150.85 \mathrm{mAh} \mathrm{g}^{-1}, 132.83 \mathrm{mAh} \mathrm{g}^{-1}, 146.46 \mathrm{mAh} \mathrm{g}^{-1}$, and $118.24 \mathrm{mAh} \mathrm{g}^{-1}$, respectively. The capacity retention is thus $93.4 \%, 92.6 \%, 84.8 \%$, and $78.7 \%$ for the respective rates. From the experimental results, it can be seen that the discharge capacity of the button cell based on the PAN/TPU/PS GPE decreases with increasing rate, especially at $1.0 \mathrm{C}$. This is mainly because a large current density increases the degree of polarisation of the battery.

\section{Conclusion}

Membranes based on PAN/TPU, TPU/PS, PAN/PS, and PAN/ TPU/PS are prepared by electrospinning. The PAN/TPU/PS electrospun membrane has the highest ionic conductivity of the different membranes at $3.83 \times 10^{-3} \mathrm{~S} \mathrm{~cm}^{-1}$, and an electrochemical stability of $5.8 \mathrm{~V}$. The SEM images and porosity measurements showed that the electrospun membranes have a uniform and highly interconnected porous structure. Simultaneously, the blend/composite membranes have excellent mechanical properties $(9.86 \mathrm{MPa})$ and elongation $(115 \%)$. In addition, in battery tests, the $\mathrm{Li} / \mathrm{GPE} / \mathrm{LiFePO}_{4}$ cell shows first charge and discharge capacities of $161.70 \mathrm{mAh} \mathrm{g}^{-1}$ and $161.44 \mathrm{mAh} \mathrm{g}^{-1}$ at the $0.1 \mathrm{C}$ rate, which represents $95 \%$ of the theoretical value. After 50 cycles, the cycle performance of the button battery based on the PAN/TPU/PS GPE has the largest capacity retention of the different GPEs at $93.4 \%$ and a stable cycle performance. All of the results demonstrate that the PAN/TPU/PS-based GPE is an ideal choice for use in LIBs.

Funding information The study received financial support from the Youth Project of National Nature Science Foundation of China (Grant No. 51103124 and No. 51203131) and Hunan Province Universities Innovation Platform of Open Fund Project (11K067).

Open Access This article is distributed under the terms of the Creative Commons Attribution 4.0 International License (http:// creativecommons.org/licenses/by/4.0/), which permits unrestricted use, distribution, and reproduction in any medium, provided you give appropriate credit to the original author(s) and the source, provide a link to the Creative Commons license, and indicate if changes were made.

\section{References}

1. Yan JD (2014) Current status and development analysis of lithiumion batteries. Acta Aeronaut Astronaut Sin 35(10):2767-2775

2. Goodenough JB, Park KS (2013) The Li-ion rechargeable battery: a perspective. J Am Chem Soc 135(4):1167-1176

3. Choi JW, Aurbach D (2016) Promise and reality of post-lithium-ion batteries with high energy densities. Nat Rev Mater 1(4):16013

4. Blomgren GE (2017) The development and future of lithium-ion batteries. J Electrochem Soc 164:A5019-A5025

5. Stephan AM (2006) Review on gel polymer electrolytes for lithium batteries. Eur Polym J 42(1):21-42

6. Ramesh S, Wen LC (2010) Investigation on the effects of addition of $\mathrm{SiO}_{2}$ nanoparticles on ionic conductivity, FTIR, and thermal properties of nanocomposite PMMA- $\mathrm{LiCF}_{3} \mathrm{SO}_{3}-\mathrm{SiO}_{2}$. Ionics 16(3):255-262

7. Ramesh S, Liew CW, Ramesh K (2011) Evaluation and investigation on the effect of ionic liquid onto PMMA-PVC gel polymer blend electrolytes. J Non-Cryst Solids 357(10):2132-2138

8. Adebahr J, Byrne N, Forsyth M, MacFarlane DR, Jacobsson P (2003) Enhancement of ion dynamics in PMMA-based gels with addition of $\mathrm{TiO}_{2}$ nanoparticles. Electrochim Acta 48(14):2099 2103

9. Nicotera I, Coppola L, Oliviero C et al (2006) Investigation of ionic conduction and mechanical properties of PMMA-PVdF blendbased polymer electrolytes. Solid State Ionics 177(5):581-588

10. Uma T, Mahalingam T, Stimming U (2005) Conductivity studies on poly(methyl methacrylate) $-\mathrm{Li}_{2} \mathrm{SO}_{4}$ polymer electrolyte systems . Mater Chem Phys 90(2):245-249

11. Kim HS, Kum KS, Cho WI, Cho BW, Rhee HW (2003) Electrochemical and physical properties of composite polymer electrolyte of poly(methyl methacrylate) and poly(ethylene glycol diacrylate). J Power Sources 124(1):221-224

12. Kim JK, Cheruvally G, Li X, Ahn JH, Kim KW, Ahn HJ (2008) Preparation and electrochemical characterization of electrospun, microporous membrane-based composite polymer electrolytes for lithium batteries. J Power Sources 178(2):815-820

13. Zhang P, Yang L, Li L et al (2011) Enhanced electrochemical and mechanical properties of $\mathrm{P}(\mathrm{VDF}-\mathrm{HFP})$-based composite polymer electrolytes with $\mathrm{SiO}_{2}$ nanowires. J Membr Sci 379(1):80-85

14. Watanabe M, Kanba M, Nagaoka K, Shinohara I (2010) Ionic conductivity of hybrid films based on polyacrylonitrile and their battery application. J Appl Polym Sci 27(11):4191-4198

15. Appetecchi GB, Croce F, Romagnoli P et al (1999) Highperformance gel-type lithium electrolyte membranes. Electrochem Commun 1(2):83-86

16. Akashi H, Sekai K, Tanaka KI (1998) A novel fire-retardant polyacrylonitrile-based gel electrolyte for lithium batteries. Electrochim Acta 43(10):1193-1197

17. Tsutsumi H, Matsuo A, Takase K, Doi S, Hisanaga A, Onimura K, Oishi T (2000) Conductivity enhancement of polyacrylonitrilebased electrolytes by addition of cascade nitrile compounds. Power Sources 90:33-38

18. Cao L, Yang M, Wu D, Lyu F, Sun Z, Zhong X, Pan H, Liu H, Lu Z (2017) Biopolymer-chitosan based supramolecular hydrogels as solid-state electrolytes for electrochemical energy storage. Chem Commun 53(10):1615-1618 
19. Missan HPS, Sekhon SS (2005) Study of enhanced dissociation of aliphatic dicarboxylic acids with PVDF addition in polymer gel electrolytes. J Mater Sci 40(14):3771-3775

20. Zhang MY, Li MX, Chang Z, Wang YF, Gao J, Zhu YS, Wu YP, Huang W (2017) A sandwich PVDF/HEC/PVDF gel polymer electrolyte for lithium ion battery. Electrochim Acta 245:752-759

21. Tatsuma T, Taguchi M, Iwaku M, Sotomura T, Oyama N (1999) Inhibition effects of polyacrylonitrile gel electrolytes on lithium dendrite formation. J Electroanal Chem 472(2):142-146

22. Abraham K, Alamgir M (1990) $\mathrm{Li}^{+}$-conductive solid polymer electrolytes with liquid-like conductivity. J Electrochem Soc 137(5): $1657-1658$

23. Jiang S, Duan G, Hou H, Greiner A, Agarwal S (2012) Novel layerby-layer procedure for making nylon- 6 nanofiber reinforced high strength, tough, and transparent thermoplastic polyurethane composites. ACS Appl Mater Interfaces 4(8):4366-4372

24. Wu N, Cao Q, Wang X, Chen Q (2011) Study of a novel porous gel polymer electrolyte based on TPU/PVdF by electrospinning technique. Solid State Ionics 203(1):42-46

25. Kuo HH, Chen WC, Wen TC (2002) Gopalan, a novel composite gel polymer electrolyte for rechargeable lithium batteries. J Power Sources 110:27-33

26. Heumen JV, Wieczorek W, Siekierski M et al (1995) Conductivity and morphological studies of TPU-NH4CF3SO3 polymeric electrolytes. J Phys Chem 99(41):15142-15152

27. Du YL, Wen TC (2001) The feasibility study of composite electrolytes comprising thermoplastic polyurethane and poly(ethylene oxide). J Mater Chem \& Phy 71(1):62-69

28. Santhosh P, Vasudevan T, Gopalan A et al (2006) Preparation and characterization of polyurethane/poly(vinylidene fluoride) composites and evaluation as polymer electrolytes. J Mater Sci \& Eng B 135(1):65-73

29. Wu N, Jing B, Cao Q, Wang XY, Kuang H, Wang Q (2012) A novel electrospun TPU/PVDF porous fibrous polymer electrolyte for lithium-ion batteries. J Appl Polym Sci 125(4):2556-2563

30. Lu QW, Hernandezhernandez ME, Macosko CW (2003) Explaining the abnormally high flow activation energy of thermoplastic polyurethanes. Polymer 44(11):3309-3318
31. Palanivelu K, Sivaraman P, Reddy MD (2002) Studies on thermoplastic polyurethane toughened poly(butylene terephthalate) blends. Polym Test 21(3):345-351

32. Wang X, Luo X (2004) A polymer network based on thermoplastic polyurethane and ethylene-propylene-diene elastomer via melt blending: morphology, mechanical properties, and rheology. Eur Polym 40:2391-2399

33. Wang X, Luo X, Wang X (2005) Study on blends of thermoplastic polyurethane and aliphatic polyester: morphology, rheology, and properties as moisture vapor permeable films. Polym Test 24(1): $18-24$

34. Wu N, Cao Q, Wang X, Li X, Deng H (2011) A novel highperformance gel polymer electrolyte membrane basing on electrospinning technique for lithium rechargeable batteries. J Power Sources 196(20):8638-8643

35. Salthammer T (2013) Formaldehyde in the ambient atmosphere: from an indoor pollutant to an outdoor pollutant? Angew Chem 52(12):3320-3327

36. Bai L, Gu J, Huan S, Li Z (2014) Aqueous poly(vinyl acetate)based core/shell emulsion: synthesis, morphology, properties and application. RSC Adv 4(52):27363-27380

37. Richardlacroix M, Pellerin C (2015) Partial disentanglement in continuous polystyrene electrospun fibers. Macromolecules 48(1):3742

38. Huan S, Liu G, Han G, Cheng W, Fu Z, Wu Q, Wang Q (2015) Effect of experimental parameters on morphological, mechanical and hydrophobic properties of electrospun polystyrene fibers. Materials 8(5):2718-2734

39. Reneker DH, Yarin AL (2008) Electrospinning jets and polymer nanofibers. Polymer 49(10):2387-2425

40. Idris NH, Rahman MM, Wang JZ, Liu HK (2012) Microporous gel polymer electrolytes for lithium rechargeable battery application. J Power Sources 201:294-300

Publisher's note Springer Nature remains neutral with regard to jurisdictional claims in published maps and institutional affiliations. 